\title{
Biomechanical modelling of the facet joints: a review of methods and validation processes in finite element analysis
}

\author{
Marlène Mengoni ${ }^{1} \mathbb{D}$
}

Received: 7 September 2020 / Accepted: 4 November 2020 / Published online: 22 November 2020

(c) The Author(s) 2020

\begin{abstract}
There is an increased interest in studying the biomechanics of the facet joints. For in silico studies, it is therefore important to understand the level of reliability of models for outputs of interest related to the facet joints. In this work, a systematic review of finite element models of multi-level spinal section with facet joints output of interest was performed. The review focused on the methodology used to model the facet joints and its associated validation. From the 110 papers analysed, 18 presented some validation of the facet joints outputs. Validation was done by comparing outputs to literature data, either computational or experimental values; with the major drawback that, when comparing to computational values, the baseline data was rarely validated. Analysis of the modelling methodology showed that there seems to be a compromise made between accuracy of the geometry and nonlinearity of the cartilage behaviour in compression. Most models either used a soft contact representation of the cartilage layer at the joint or included a cartilage layer which was linear elastic. Most concerning, soft contact models usually did not contain much information on the pressure-overclosure law. This review shows that to increase the reliability of in silico model of the spine for facet joints outputs, more needs to be done regarding the description of the methods used to model the facet joints, and the validation for specific outputs of interest needs to be more thorough, with recommendation to systematically share input and output data of validation studies.
\end{abstract}

Keywords Facet joints · Validation $\cdot$ Variability $\cdot$ Finite element $\cdot$ Reproducibility

\section{Introduction}

There is an increased interest in analysis of the facet joints in biomechanical studies of the spine. The facet joints (zygapophysial joints) constitute with the intervertebral disc the three joints complex of the functional spinal unit (motion segment). They are synovial joints located posterior to the vertebrae and the intervertebral disc and contribute to the motion and stability of the spine. Osteoarthritis of the facet joints is thought to be a widespread cause of back pain (Gellhorn et al. 2013), in part because of its high prevalence and early development, with facet joints degeneration associated with a radiological narrowing of the joint space (Pathria et al. 1987). Studies have shown association between intervertebral disc degeneration and facet osteoarthritis, even though the latter can exist without the former (Jaumard et al.

Marlène Mengoni

m.mengoni@leeds.ac.uk

1 Institute of Medical and Biological Engineering, University of Leeds, Leeds, UK 2011b; Gellhorn et al. 2013). Moreover, some disc treatments leading to adjacent disc disease are thought to exacerbate facet osteoarthritis (O'Leary et al. 2018).

Finite element analysis of spine biomechanics can be useful to assess different scenario for a range of spinal disorders or associated surgical interventions (e.g. among many others Rohlmann et al. 2006b; Bashkuev et al. 2018 or Ottardi et al. 2016; Calvo-Echenique et al. 2018, respectively). It can complement in vitro or in vivo experiments with scenario testing and inclusion of a wider variation in the anatomy and tissue degeneration.

Key requirements for using in silico models in clinical or preclinical contexts are the assessment of their credibility defined from a clear understanding of their applicability (Morrison et al. 2019) and known validation processes (Jones and Wilcox 2008; Henninger et al. 2010). Validation of in silico model is the process of making sure that the right equations are solved, and the correct parameters are used for a given scenario. A model is never "valid" for all possible scenarios and applications; a validation process is linked to a specific question of interest (Viceconti et al. 2020). 
Finite element models of the multi-level spinal unit include different levels of complexity, either in the material behaviour or in the type of tissues included in models. Most finite element models of the human spine are validated against range of motion (e.g. Ayturk and Puttlitz 2011; Azari et al. 2018; Barthelemy et al. 2016; Holzapfel and Stadler 2006; Khoddam-Khorasani et al. 2018; Noailly et al. 2012; Rohlmann et al. 2006a; Schmidt et al. 2013), facet joint forces (e.g. Ayturk and Puttlitz 2011; Azari et al. 2018; Barthelemy et al. 2016) or intervertebral disc pressure (e.g. Ayturk and Puttlitz 2011; Azari et al. 2018; Khoddam-Khorasani et al. 2018; Liu et al. 2018; Rohlmann et al. 2006a); with the majority of work comparing their outcome to experimental or computational data available in the literature. This provides a validation process which gives confidence that models can predict outcomes within a range of values for given outputs of interest.

The aim of this review was to assess the methods used in modelling the facet joints in finite element models of multilevel spinal units, and the validation processes used for the facet joints biomechanics in such models. To avoid assessing the same model used for different clinical scenarios, only original models (with model development presented for the first time) and their validation studies were included in this review. With its focus on methods and validation, this work is complementary to recent reviews on the role of each spinal component in load transmission (Ghezelbash et al. 2020), on the structure-function relationship of the facet joints (O'Leary et al. 2018), or on finite element analysis of the cervical spine biomechanics (Suarez-Escobar and Rendon-Velez 2018; Kim et al. 2018).

\section{Methods}

Three databases (PubMed, Web of Science and Scopus) were searched for papers up to August 2020 with keywords ["finite element" or computational] AND ["facet joint" or zygapophysial] (Fig. 1). Papers not written in English, duplicates, and conference proceedings were excluded. Due to a previous literature search supporting a computational validation study for ovine facet joints in 2015 (Mengoni et al. 2016), different criteria were used to include papers based on their titles and abstracts up to 2014 or from 2015: the more recent were screened for containing keywords "finite element" or "in silico", while the older ones were screened to also contain explicit information about facet joints outputs and model development (by opposition to using an existing model). From the remaining papers, 11 were excluded because they were not available through the University library $(n=5)$, were reviews $(n=4)$ or were animal models $(n=2)$. Full papers were screened to include only those which were studies

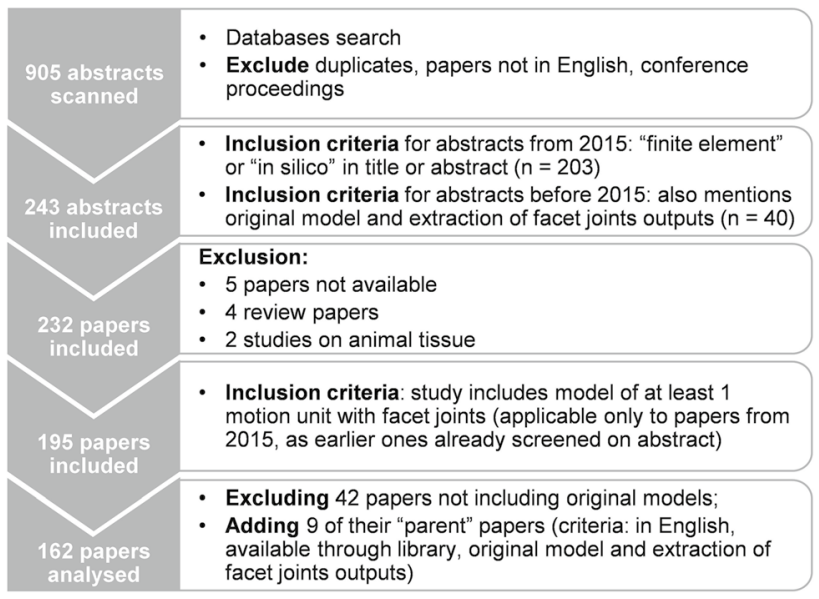

Fig. 1 Inclusion and exclusion criteria

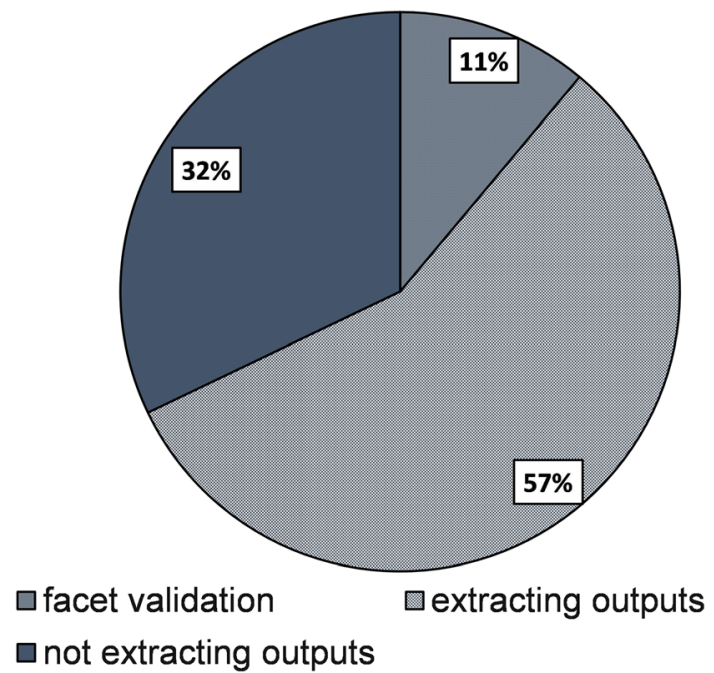

Fig. 2 Analysed papers contained studies which did not extract outputs of interest for facet joints $(32 \%)$ or studies with validation of facet joints biomechanics (11\%)

of at least one functional unit with facet joints $(n=195)$ and presented original models $(n=153)$. From papers excluded because of the latter criteria, nine new "parent" papers were included, after screening for explicitly containing information about facet joints outputs and new model development.

Of the 162 analysed papers (Fig. 2), 52 did not contain outputs of interest related to the facet joints (all from 2015 given the differential in inclusion criteria) and are not reported here. In summary, from an initial set of 905 abstracts, 110 studies were analysed in this review (47 published before 2015), 18 of which contained some validation method on facet joints biomechanical behaviour: just under one in six original models using facet outputs had some validation for the facet joints. 
Key aspects of the modelling methodology for facet joints were extracted: geometry representation, contact model, and, when relevant, cartilage material model. Attention was paid to the validation processes for facet joints outputs of interest.

\section{Methodologies for facet joints models}

\subsection{Facet joint representation}

Of studies reporting relevant information, just over half

Table 1 Contact models for studies which do not explicitly include a cartilage layer at the facet joints (empty cells refer to a lack of relevant information)

\begin{tabular}{|c|c|c|}
\hline References & Friction model & Pressure-overclosure information \\
\hline Azari et al. (2018) & Frictionless & Initial joint space of $0.6 \mathrm{~mm}$ \\
\hline Campbell et al. (2016) & Frictionless & Initial joint space as per $\mathrm{CT}$; linear formulation \\
\hline Cao et al. (2020) & & Initial joint space of $0.5 \mathrm{~mm}$ \\
\hline Chen et al. (2002) & & Initial joint space of $1 \mathrm{~mm}$ \\
\hline Chen et al. (2009) & Friction coefficient of 0.1 & Initial joint space of $0.5 \mathrm{~mm}$ \\
\hline Du et al. (2016b) & Frictionless & Initial joint space of $0.5 \mathrm{~mm}$ \\
\hline Galbusera et al. (2008) & Frictionless & \\
\hline Goel et al. (1988) & Frictionless & Initial joint space of $0.45 \mathrm{~mm}$ \\
\hline Guo et al. (2007) & Frictionless & \\
\hline Guo and Li (2020) & Frictionless & Initial joint space of $0.5 \mathrm{~mm}$ \\
\hline Khoddam-Khorasani et al. (2018) & & Max gap of $1.25 \mathrm{~mm}$ \\
\hline Kim et al. (2012) & & Exponential formulation \\
\hline Kim et al. (2017) & Frictionless & Exponential formulation \\
\hline Kong et al. (1998) & & $\begin{array}{l}\text { Initial joint space of } 1.25 \mathrm{~mm} \text {, contact initiated at gap of } 0.75 \mathrm{~mm} \text {, exponential } \\
\text { formulation, pressure at zero gap of } 35 \mathrm{GPa}\end{array}$ \\
\hline Liu et al. (2011) & Friction coefficient of 0.1 & Initial joint space of $0.5 \mathrm{~mm}$ \\
\hline Liu et al. (2018) & Frictionless & Max gap of $1.5 \mathrm{~mm}$ \\
\hline Liu et al. (2020) & Frictionless & Initial joint space of $0.5 \mathrm{~mm}$ \\
\hline Mustafy et al. (2014) & Frictionless & \\
\hline Naserkhaki et al. (2016) & Frictionless & Max gap of $2 \mathrm{~mm}$ \\
\hline Niemeyer et al. (2012) & Frictionless & $\begin{array}{l}\text { Initial joint space of } 0.01 \mathrm{~mm} \text { to } 0.4 \mathrm{~mm} \text { (uniform probability distribution), } \\
\text { contact initiated for overclosure of } 0.01 \text { to } 0.3 \mathrm{~mm} \text { (uniform probability distri- } \\
\text { bution), exponential formulation, pressure at zero gap of } 170 \mathrm{MPa}\end{array}$ \\
\hline Nikkhoo et al. (2019) & Frictionless & Initial joint space of $0.3 \mathrm{~mm}$, exponential formulation \\
\hline Nikkhoo et al. (2020) & Frictionless & $\begin{array}{l}\text { Initial joint space of } 0.5 \mathrm{~mm} \text {, contact initiated at gap of } 0.5 \mathrm{~mm} \text {, exponential } \\
\text { formulation, pressure at zero gap of } 120 \mathrm{MPa}\end{array}$ \\
\hline Rohlmann et al. (2006b) & & $\begin{array}{l}\text { Initial joint space of } 0.5 \mathrm{~mm} \text {, gap/pressure curve with a pressure at zero gap of } \\
12 \mathrm{GPa}\end{array}$ \\
\hline Rundell et al. (2011) & Frictionless & \\
\hline Sharma et al. (1995) & & $\begin{array}{l}\text { Initial joint space of } 0.6 \mathrm{~mm} \text {, contact initiated at gap of } 0.4 \mathrm{~mm} \text {, gap/pressure } \\
\text { curve with a pressure at zero gap of } 12 \mathrm{GPa}\end{array}$ \\
\hline Shen et al. (2019) & Frictionless & \\
\hline Shirazi-Adl et al. (1986) & Frictionless & \\
\hline Shirazi-Adl and Drouin (1987) & Frictionless & Initial joint space of $1 \mathrm{~mm}$, max overclosure $0.5 \mathrm{~mm}$ \\
\hline Shirazi-Adl (1994) & Frictionless & $\begin{array}{l}\text { Contact initiated at overclosure of } 1.25 \mathrm{~mm} \text {, compression moduli of } 75 \text { and } \\
150 \mathrm{MPa}\end{array}$ \\
\hline Sterba et al. (2019) & Frictionless & \\
\hline Teo et al. (2003) & Frictionless & Normal penalty increasing linearly from 0 to $12 \mathrm{GPa}$ at overclosure of $0.2 \mathrm{~mm}$ \\
\hline Tsouknidas et al. (2015) & Friction coefficient of 0.1 & Initial joint space of $0.5 \mathrm{~mm}$ \\
\hline Wang et al. (1997) & Frictionless & Initial joint space of $0.4 \mathrm{~mm}$, pressure at zero gap $1.6 \mathrm{MPa}$ \\
\hline Wang et al. (2020) & Friction coefficient of 0.1 & \\
\hline Xu et al. (2017) & Frictionless & Initial joint space of $0.5 \mathrm{~mm}$ \\
\hline Zhu et al. (2017) & Frictionless & Initial joint space $0.5 \mathrm{~mm}$ \\
\hline
\end{tabular}


( $n=50 / 95$, Table 1$)$ did not include the cartilage explicitly but represented its function through contact pairs and a soft-contact pressure-overclosure model. The studies which explicitly included cartilage ( $n=45 / 95$, Table 2 ) usually modelled its behaviour as a linear elastic material $(n=37 / 45)$. Quite a few studies ( $n=15 / 110$, Table 3$)$ did not include sufficient information to know how the facet joint was represented (i.e. studies that may mention some information about friction but not if cartilage was represented explicitly or through a soft contact model, or that mention the presence of cartilage without information on material model used).

When cartilage was included explicitly, it was always reconstructed from the bone anatomy, and from reported observation of facet joint space and/or cartilage thickness in facet joints.

\subsection{Facet joint contact model}

Whether or not the cartilage is included explicitly, a contact model is required to represent the interaction between opposite facet surfaces.

When cartilage was not included, the pressure-overclosure model in the soft contact formulation represents both the direct contact behaviour and the compliance of the cartilage in compression. It was rarely described with sufficient details (Table 1): most studies included information about initial joint space (initial bony gap with no physical cartilage

Table 2 Material model and parameters, and friction models of studies explicitly including a cartilage layer at the facets (empty cells refer to a lack of relevant information)

\begin{tabular}{|c|c|c|}
\hline References & Friction model & Cartilage material model \\
\hline Bashkuev et al. $(2018,2020)$ & Frictionless & Linear elastic: $E$ variable, $v=0.3$ \\
\hline Cai et al. (2020) & Friction coefficient of 0.01 & Linear elastic: $E=10 \mathrm{MPa}, v=0.4$ \\
\hline $\begin{array}{l}\text { Calvo-Echenique et al. (2018); Kang et al. (2015, 2017); Kim } \\
\text { et al. (2013); Schmidt et al. (2012) }\end{array}$ & Frictionless & Linear elastic: $E=35 \mathrm{MPa}, v=0.4$ \\
\hline Ezquerro et al. (2011) & Frictionless & Linear elastic \\
\hline Guo et al. (2019) & Frictionless & Linear elastic: $E=10 \mathrm{kPa}$ \\
\hline $\begin{array}{l}\text { Huang et al. (2018); Li et al. (2017b, 2018); Mo et al. (2017); } \\
\text { Rong et al. (2017); Wu et al. (2017) }\end{array}$ & Frictionless & Linear elastic: $E=10.4 \mathrm{MPa}, v=0.4$ \\
\hline John et al. (2018) & & Linear elastic: $E=10 \mathrm{MPa}, v=0.3$ \\
\hline Kang et al. (2010) & & Linear elastic: $E=0.5 \mathrm{MPa}, v=0.45$ \\
\hline Lee et al. (2011, 2016); Li et al. (2017c); Sun et al. (2020) & & Linear elastic: $E=10.4 \mathrm{MPa}, \nu=0.4$ \\
\hline Li et al. (2017a) & Friction coefficient of 0.07 & Linear elastic: $E=10.4 \mathrm{MPa}, v=0.4$ \\
\hline Li et al. (2019) & Frictionless & Linear elastic: $E=10 \mathrm{MPa}, v=0.4$ \\
\hline Mesfar and Moglo (2013) & & Linear elastic: $E=10 \mathrm{MPa}, v=0.45$ \\
\hline Mills and Sarigul-Klijn (2019) & & Linear elastic: $E=35 \mathrm{MPa}, v=0.4$ \\
\hline Moumene and Geisler (2007); Park et al. (2013b) & & Linear elastic: $E=11 \mathrm{MPa}, v=0.4$ \\
\hline Ottardi et al. (2016) & & Linear elastic: $E=23.8 \mathrm{MPa}, v=0.4$ \\
\hline Panzer and Cronin (2009) & $\begin{array}{l}\text { Squeeze-film-bearing } \\
\text { model + frictionless }\end{array}$ & Linear elastic: $E=10 \mathrm{MPa}, v=0.4$ \\
\hline Park et al. (2013a) & Frictionless & Linear elastic: $E=11 \mathrm{MPa}, v=0.4$ \\
\hline Tang and Meng (2011) & Frictionless & Linear elastic: $E=3500 \mathrm{MPa}, \nu=0.25$ \\
\hline Wang et al. (2013) & Frictionless & Linear elastic: $E=75 \mathrm{MPa}, v=0.4$ \\
\hline Wang et al. (2016a) & Frictionless & Linear elastic \\
\hline Wang et al. (2016b) & Friction coefficient of 0.01 & Linear elastic: $E=23.8 \mathrm{MPa}, v=0.4$ \\
\hline Xin-Feng et al. (2020) & Friction coefficient of 0.1 & Linear elastic: $E=10.4 \mathrm{MPa}, v=0.4$ \\
\hline Zhou et al. (2020) & Friction coefficient of 0.2 & Linear elastic: $E=50 \mathrm{MPa}, v=0.3$ \\
\hline Ayturk and Puttlitz (2011); Du et al. (2016a) & Frictionless & Neo Hooke \\
\hline Holzapfel and Stadler (2006) & Friction coefficient of 0.06 & Neo Hooke \\
\hline Schmidt et al. (2013) & Frictionless & Mooney-Rivlin 1st order \\
\hline Barthelemy et al. (2016) & Frictionless & Mooney-Rivlin 2nd order \\
\hline Noailly et al. (2012) & & Mooney-Rivlin 2nd order, incompressible \\
\hline Noailly et al. (2007) & & $\begin{array}{l}\text { Asymmetric tension/compression, with } \\
\text { hypoeleastic cartilage in compression }\end{array}$ \\
\hline Hussain et al. (2010) & & Poroelastic using: $E=10.4 \mathrm{MPa}, v=0.4$ \\
\hline
\end{tabular}


Table 3 Contact information of studies which are unclear about the representation of cartilage (empty cells refer to a lack of relevant information)

\begin{tabular}{ll}
\hline References & Friction model \\
\hline Chen et al. (2015) & Friction coefficient of 0.1 \\
Choi et al. (2016) & Frictionless \\
Choi et al. (2017) & \\
Chuang et al. (2012) & Frictionless, initial facet space $0.5 \mathrm{~mm}$ \\
Guo and Li (2019) & Frictionless \\
Kong et al. (1996) & \\
Kosalishkwaran et al. (2019) & Frictionless \\
Li et al. (2020) & \\
Lin et al. (2014) & Friction coefficient of 0.1 \\
Yang and King (1984) & \\
Yu et al. (2020) & Friction coefficient of 0.1 \\
Yuchi et al. (2019) & Friction coefficient of 0.01 , initial \\
& facet space 0.5 mm \\
Wu et al. (2017) & Frictionless \\
Zhu et al. (2020) & Friction coefficient of 0.1 \\
Zhang et al. (2018) & Frictionless \\
Zhu et al. (2015) & \\
\hline
\end{tabular}

present) or maximum overclosure values (max gap) but usually did not provide much information about the pressureoverclosure relationship. Fourteen studies (out of 49) did not provide any other information than using a "soft contact" or "non-linear contact" formulation (Aroeira et al. 2018; Bermel et al. 2018; Campbell and Petrella 2016; Charles et al. 2013; Cheung et al. 2003; Deng et al. 2017; Goto et al. 2002; Kim et al. 1991; Lo et al. 2019; Pitzen et al. 2002; Song et al. 2014, 2018; Teo and Ng 2001; Zeng et al. 2017). Only six of the 50 models with cartilage behaviour modelled as soft contact reported all required information on the pressureoverclosure law, of which only four also reported friction behaviour.

Of studies which included information on the friction model (Table $1, n=30 / 35$ studies with soft contact and Table 2, $n=31 / 45$ studies with cartilage), a majority assumed the contact behaviour to be frictionless ( $n=50 / 61$ ), while only eleven included some friction (with a friction coefficient ranging from 0.01 to 0.2 ). None of the model with friction specified the type of friction law used.

\subsection{Cartilage material model}

Of studies which incorporate a 3D deformable cartilage layer, only one did not consider the cartilage as a purely elastic material, but used a poroelastic model instead (Hussain et al. 2010). Most other studies used a linear elastic material law with a large variation in Young's modulus (median 10.4 $\mathrm{MPa}$, range $10 \mathrm{kPa}-3.5 \mathrm{GPa}$ ) and Poisson's ratio (median 0.4 , range $0.25-0.45$ ). Those using a hyperelastic material law used a Neo-Hooke model or first- or secondorder Mooney-Rivlin model; only one giving information on the compressibility of the material used. Finally, only one study (Noailly et al. 2007) used a material law asymmetric in tension and compression, representing the different behaviour of the cartilage in these configurations.

\section{Validation processes used in facet joints biomechanics}

There were as many recent studies ( $n=9 / 63$ since 2015) as older ones ( $n=9 / 47$ before 2015) which included some validation of the facet joints biomechanics (Table 4). While ten studies assessed their outcomes with respect to ranges of experimental values available in the literature, 11 assessed their outcomes with respect to FE models outputs, three of which also comparing to experimental data from the literature.

The assessment of the effect of using diverse contact algorithm on facet joints biomechanics was studied by evaluating the contact pattern (Holzapfel and Stadler 2006). Of these 18 studies with validation, none also reported sensitivity analysis on facet joints inputs to outputs of interest. Only one study, whose study aim was to assess the validity of a statistical shape model, reported sensitivity to the geometry of the spinal level of interest (Campbell et al. 2016).

\subsection{Comparison with literature experimental data}

The source of experimental data from the literature used in validation work was limited, with four experimental studies used for the lumbar spine (Wilson et al. 2006; Niosi et al. 2008; Zhu et al. 2008 from the University of British Columbia, and Sawa and Crawford 2008 from St. Joseph's Hospital and Medical Center) and one for the cervical spine (Jaumard et al. 2011a).

When comparing outcome of FE models with otherwise published experimental data, all lumbar spine studies used one source of data (Wilson et al. 2006), often alongside others, which includes in its discussion comments about experimental accuracy, reporting a likely overestimation of facet joints forces. This aspect was not acknowledged in validation studies which rarely consider experimental error as a source of error on the validation of computational models. Moreover, for L3/L4, some studies compared their results to both Wilson et al. (2006) and Sawa and Crawford (2008) for which the latter has a mean value almost half of the former. In that case, computational results are usually closer to the highest values (Wilson et al. 2006) than the lower ones 
Table 4 Study aim and validation work performed for the 18 studies mentioning some validation of facet joints biomechanics (references denoted with * are included in the comparison work in Dreischarf et al. 2014)

\begin{tabular}{|c|c|c|}
\hline References & Study aim & Validation work for facet joints \\
\hline \multicolumn{3}{|c|}{ Comparison of facet joint force or pressure } \\
\hline Azari et al. (2018) & $\begin{array}{l}\text { Estimate internal stresses and strains under } \\
\text { realistic load conditions }\end{array}$ & $\begin{array}{l}\text { Pooled range of values from eight FE models } \\
\text { (Dreischarf et al. 2014) }\end{array}$ \\
\hline Ayturk and Puttlitz (2011)* & Validation work & $\begin{array}{l}\text { Experimental data (Wilson et al. 2006; Niosi } \\
\text { et al. 2008; Sawa and Crawford 2008) }\end{array}$ \\
\hline Barthelemy et al. (2016) & Validation of composition-based disc model & $\begin{array}{l}\text { Experimental data (Wilson et al. 2006; Niosi } \\
\text { et al. 2008; Zhu et al. 2008); computational } \\
\text { data (Noailly et al. 2012) }\end{array}$ \\
\hline Campbell et al. (2016) & Development of statistical shape modelling & $\begin{array}{l}\text { Experimental data (Wilson et al. 2006; Niosi } \\
\text { et al. 2008; Sawa and Crawford 2008) }\end{array}$ \\
\hline Chen et al. (2009) & Comparison between TDR and fusion & FE models (Chen et al. 2002; Shirazi-Adl 1994) \\
\hline Goel et al. (1988) & Effect of fixation device & $\begin{array}{l}\text { FE models (Shirazi-Adl and Drouin 1987; Yang } \\
\text { and King 1984) }\end{array}$ \\
\hline Guo et al. (2007) & Effect of denucleation with vibration & FE model (Shirazi-Adl and Drouin 1987) \\
\hline Guo and Li (2020) & Validation in static and dynamic conditions & $\begin{array}{l}\text { Experimental data (Wilson et al. 2006; Niosi } \\
\text { et al. 2008; Sawa and Crawford 2008) }\end{array}$ \\
\hline Kim et al. (2013) & $\begin{array}{l}\text { Effect of facet joints orientation and facet } \\
\text { tropism }\end{array}$ & Experimental data (Wilson et al. 2006) \\
\hline Khoddam-Khorasani et al. (2018) & Coupling passive FE and active MSK & $\begin{array}{l}\text { Pooled range of values from eight FE models } \\
\text { (Dreischarf et al. 2014) }\end{array}$ \\
\hline Liu et al. (2011)* & Effect of stabilisation system & $\begin{array}{l}\text { FE models (Shirazi-Adl et al. 1986; Chen et al. } \\
\text { 2009) }\end{array}$ \\
\hline Mills and Sarigul-Klijn (2019) & Validation work & $\begin{array}{l}\text { Pooled range of values from eight FE models } \\
\text { (Dreischarf et al. 2014) and experimental data } \\
\text { (Wilson et al. 2006) }\end{array}$ \\
\hline Mustafy et al. (2014) & Effect of impact loading rates on load sharing & Experimental data (Jaumard et al. 2011a) \\
\hline Naserkhaki et al. (2016) & Assessment load share in flexion-extension & $\begin{array}{l}\text { Pooled range of values from eight FE models } \\
\text { (Dreischarf et al. 2014) and experimental data } \\
\text { (Wilson et al. 2006) }\end{array}$ \\
\hline Nikkhoo et al. (2020) & Effect of lordosis on fusion & $\begin{array}{l}\text { Pooled range of values from eight FE models } \\
\text { (Dreischarf et al. 2014) }\end{array}$ \\
\hline Wang et al. (1997) & Validation of a viscoelastic model & FE model (Shirazi-Adl and Drouin 1987) \\
\hline Xu et al. (2017) & Validation work from multiple subjects & $\begin{array}{l}\text { Experimental data (Wilson et al. 2006; Niosi } \\
\text { et al. 2008; Sawa and Crawford 2008) }\end{array}$ \\
\hline \multicolumn{3}{|l|}{ Other comparison } \\
\hline Holzapfel and Stadler (2006) & Role of facet curvature & $\begin{array}{l}\text { Qualitative comparison of "waviness" of contact } \\
\text { pattern }\end{array}$ \\
\hline
\end{tabular}

(Sawa and Crawford 2008), while the corresponding L1/L2 is validated against Sawa and Crawford (2008)'s data.

Most FE studies compared their outputs with literature reporting data for the same spinal levels (L1-2 or L3-4), however, some reported validation while mixing experimental data from several levels (e.g. Mustafy et al. 2014 comparing one cervical level with the range reported for $\mathrm{C} 2-\mathrm{C} 6$ ), artificially increasing the range of validity.

\subsection{Comparison with literature computational data}

Eleven studies provided validation of facet joints outputs against computational data. All validation studies against computational data were able to replicate exactly boundary and loading conditions with respect to study providing target values but none of the target computational studies was specifically validated for facet joints biomechanics.

Five out of six studies performed after 2014 compared their results to the pooled outcomes resulting from the comparison study of eight lumbar models (Dreischarf et al. 2014). This type of validation protocol uses an artificially large variance in the target values for validation. In particular, the range of mean facet joint force values across all eight models in extension and in axial rotation $(\sim 10 \mathrm{~N}$ to $\sim 110 \mathrm{~N}$ and $\sim 40 \mathrm{~N}$ to $\sim 135 \mathrm{~N})$ was up to twice larger than corresponding experimental data $(\sim 10 \mathrm{~N}$ to $\sim 55 \mathrm{~N}$ and $\sim 55 \mathrm{~N}$ to $\sim 115 \mathrm{~N}$, Wilson et al. 2006), defining an "easier" validation target. 
For five out of six studies performed before 2014, reference studies used were early computational studies (ShiraziAdl et al. 1986; Shirazi-Adl and Drouin 1987; Yang and King 1984) for which the accuracy of the geometry could be questioned with respect to accuracy of contact forces.

\section{Discussion}

This review of 110 papers from the last $30+$ years has shown that there is, to date, no finite element model of the human functional spinal unit (two or more levels) which provides direct validation of the facet joint behaviour. Direct validation is here defined as the direct comparison between a computational result and an experimental result of the same specimen, when the computational model and the experiment match as closely as possible (Jones and Wilcox 2008; Mengoni et al. 2017). All quantitative validation processes for the facet joints in the reviewed studies use comparison with the existing literature data, either computational data or experimental data, all assuming healthy facet joint properties. This process of indirect validation is useful to verify that model outputs are within a range of plausible values. Even when those models are built from patient-specific geometry, it does not demonstrate that the model outputs are valid for a specific geometry, or that the method is able to appropriately capture variation within the population.

One in three studies without facet joint validation focus on the effect of different constructs or disc degeneration on the facet joints. Moreover, while a clinical correlation has been established between intervertebral disc degeneration and facet joints degeneration (Jaumard et al. 2011b; Gellhorn et al. 2013), studies modelling degenerated disc and also including degeneration of the facet joint cartilage material properties or friction behaviour are only those which perform statistical sweeps. As such, most studies evaluate the effect of a disruption for which there is no initial indication of baseline validity or without including concomitant factors. While some qualitative comparison may still be appropriate, there is no indication that quantitative assessment should be taken for granted.

There is often a lack of critical analysis about the methodology used. For example, the facet joint being a synovial joint, it has almost perfect lubrication (Guilak 2005). As such, when healthy, it is likely that the friction coefficient is well below 0.05 . Using a higher friction coefficient may be the result of needing to reduce sliding for computational stability rather than a representation of a physical characteristic. When such parameters choices do not seem to be based on the physics of the problem, more should be done in discussing "the art of modelling" and modelling assumptions openly (i.e. choices made so that a model solution can converge). This would contribute to a more honest discussion on the capacity of the modelling approach chosen.

Less than one in five studies provide sufficient details on the facet joint behaviour modelling assumptions (material parameters or pressure-overclosure model and computational representation of friction). This lack of information is somewhat contributing to reduced confidence in the outcomes and mostly to poor reproducibility. The lack of information on soft contact models is the most common, often only mentioning the use of "soft contact" or "nonlinear contact". This may be due to using default approaches in commercial finite element software without a clear understanding of what these are or of what they represent physically. The use of software-specific terminology reinforces that interpretation. Issues linked with poor reproducibility in joint biomechanics is not specific to modelling of the facet joints. For example, the likely shortcomings of natural knee modelling are the basis of a large multi-centre reproducibility study, assessing the effect of the "art of modelling" on model outputs variability (Erdemir et al. 2019).

There is often a trade-off between the accuracy of cartilage geometry and materials in facet joint modelling assumptions. Including a complex representation of the cartilage, combined with a nonlinear material law may increase the overall non-linearity of a computational model to a point where solving becomes too difficult. As such, models which represent the cartilage geometry explicitly often have linear material properties, while models with nonlinear soft contact assumptions do not include any inhomogeneity in the cartilage anatomy (in particular its thickness). The cartilage geometry, even when explicitly included, is always an approximation, based on general anatomical knowledge such as setting a given initial joint space or an average cartilage thickness. Sensitivity studies including heterogeneous thickness of the cartilage (Woldtvedt et al. 2011; Niemeyer et al. 2012) showed that while the ranges of motion were not altered with respect to homogeneous cartilage, outputs related to contact and load share were highly affected. Variable cartilage thickness models could be done by incorporating data from MR images to models that are often built from CT images. This comes with the difficulty of poor anatomical resolution in clinical MR (where standard MR protocols do not capture many slices within each facet joints) and may therefore be more suited for cadaveric studies where highresolution MR can be acquired with very few artefacts.

There is no extensive sensitivity study on the effect that cartilage material law has on facet outputs of interest. As the initial facet joint space and the cartilage thickness seem to have a major effect on contact pressure obtained during normal range of movements (Niemeyer et al. 2012), the effect of material law may be secondary. In theory, material models for the cartilage should represent its different behaviour in tension and compression (Noailly et al. 2007). 
Using a soft-contact model for the cartilage has the benefit to include this aspect by default, while models with an explicit representation of the cartilage should include this behaviour in the material law. This effect needs to be included if the cartilage may sustain loads which are not compressive. However, as most contact models used are frictionless and inactive once the surfaces are not overlapping, it is unlikely that the facet cartilage sustain loads other than compressive loads. As such, including the different behaviour in tension and compression may only have a secondary effect.

In a validation process comparing data to the literature, the aim is to obtain model outputs within a range of equivalent literature values. By nature of working with natural tissues and somewhat different testing protocols, there is a large variability in experimental data on facet joints found in the literature. Comparing computational outcome to experimental data obtained with a protocol as similar as the computational model is therefore critical when choosing what experimental data to use in validation studies. Data to compare against should not be chosen a-posteriori to fit computational outcomes. Computational studies are often unable to replicate facet joint forces of two adjacent levels from a unique data source. This lack of consistency between levels does not provide confidence that one model can replicate one experimental protocol but rather that models are able to replicate average values coming from different testing protocols. There is also a large variability in computational data on facet joints in the literature, which increases by including studies which are not specifically validated against facet joint outputs. Performing validation studies against computational data which is not known to be valid for facet joint outputs increases the risk of a model being wrongly deemed valid and should be avoided.

Validation can be done comparing model outcomes to equivalent data from the literature or to data corresponding directly to the specimen being modelled. While most validation studies analysed here replicate as closely as possible an equivalent experimental or computational protocol, they do not report on how sensitive the model outputs are to its inputs or which assumptions can be modified and still produce a valid outcome. When building model geometries from patient- or specimen-specific images, this means that there is no indication on the patient-specificity of the outcomes produced by a modelling method deemed to be valid with respect to literature data. A validation process comparing a model to its direct experimental equivalent has the benefit that the specificity of the validation can be assessed (Jones and Wilcox 2008). When performing such a direct validation across several specimens, it also has the advantage that it provides confidence in the ability to model the specimen-to-specimen variation in the outputs of interest (Mengoni 2020b). However, there is often a trade-off between having a model representative of a realistic, often uncertain, situation and replicating closely a given specimen and its testing conditions (Cooper et al. 2019).

While model validation is always limited to a given set of inputs and outputs, using models or methodologies outside their validation range is where computational modelling can become useful, providing new information. This should be performed with clear identification of the context of use (Viceconti et al. 2020), justifying using appropriate variation in inputs or outputs with respect to the validation study. Systematically providing comprehensive information on model methodologies ("the art of modelling") and on the physical data used in validation studies (input and output data) would provide better confidence in the context of use of "valid" models and increase the possibility to directly compare model methodologies against the same physical data. In the case of facet joints biomechanics for which no direct validation study exists, systematically sharing data, including 3D imaging, through open-repositories would allow more users to demonstrate that their model outputs are valid for specific inputs, and that their method is able to appropriately capture variation within the population.

Availability of data and material All data presented in this paper, as well as the equivalent data for the 52 studies which did not contain outputs of interest for the facet joints, are available at the University of Leeds repository (Mengoni 2020a).

\section{Compliance with ethical standards}

Conflict of interest The author declares that they have no conflict of interest.

Open Access This article is licensed under a Creative Commons Attribution 4.0 International License, which permits use, sharing, adaptation, distribution and reproduction in any medium or format, as long as you give appropriate credit to the original author(s) and the source, provide a link to the Creative Commons licence, and indicate if changes were made. The images or other third party material in this article are included in the article's Creative Commons licence, unless indicated otherwise in a credit line to the material. If material is not included in the article's Creative Commons licence and your intended use is not permitted by statutory regulation or exceeds the permitted use, you will need to obtain permission directly from the copyright holder. To view a copy of this licence, visit http://creativecommons.org/licenses/by/4.0/.

\section{References}

Aroeira R, Pertence A, Kemmoku D, Greco M (2018) The effect of hypokyphosis on the biomechanical behavior of the adolescent thoracic spine. J Braz Soc Mech Sci Eng. https://doi.org/10.1007/ s40430-018-1061-4

Ayturk UM, Puttlitz CM (2011) Parametric convergence sensitivity and validation of a finite element model of the human lumbar spine. Comput Methods Biomech Biomed Eng 14(8):695-705. https:// doi.org/10.1080/10255842.2010.493517 
Azari F, Arjmand N, Shirazi-Adl A, Rahimi-Moghaddam T (2018) A combined passive and active musculoskeletal model study to estimate 14-15 load sharing. J Biomech 70:157-165. https://doi. org/10.1016/j.jbiomech.2017.04.026

Barthelemy V, van Rijsbergen M, Wilson W, Huyghe J, van Rietbergen B, Ito K (2016) A computational spinal motion segment model incorporating a matrix composition-based model of the intervertebral disc. J Mech Behav Biomed Mater 54:194-204. https://doi. org/10.1016/j.jmbbm.2015.09.028

Bashkuev M, Reitmaier S, Schmidt H (2018) Effect of disc degeneration on the mechanical behavior of the human lumbar spine: a probabilistic finite element study. Spine J 18(10):1910-1920. https://doi.org/10.1016/j.spinee.2018.05.046

Bashkuev M, Reitmaier S, Schmidt H (2020) Relationship between intervertebral disc and facet joint degeneration: a probabilistic finite element model study. J Biomech 102:109518. https://doi. org/10.1016/j.jbiomech.2019.109518

Bermel E, Barocas V, Ellingson A (2018) The role of the facet capsular ligament in providing spinal stability. Comput Methods Biomech Biomed Eng 21(13):712-721. https://doi. org/10.1080/10255842.2018.1514392

Cai XY, Sang D, Yuchi CX, Cui W, Zhang C, Du CF, Liu B (2020) Using finite element analysis to determine effects of the motion loading method on facet joint forces after cervical disc degeneration. Comput Biol Med 116:103519. https://doi. org/10.1016/j.compbiomed.2019.103519

Calvo-Echenique A, Cegoñino J, Chueca R, del Palomar AP (2018) Stand-alone lumbar cage subsidence: a biomechanical sensitivity study of cage design and placement. Comput Methods Programs Biomed 162:211-219. https://doi.org/10.1016/j. cmpb.2018.05.022

Campbell J, Petrella A (2016) Automated finite element modeling of the lumbar spine: using a statistical shape model to generate a virtual population of models. J Biomech 49(13):2593-2599. https://doi.org/10.1016/j.jbiomech.2016.05.013

Campbell J, Coombs D, Rao M, Rullkoetter P, Petrella A (2016) Automated finite element meshing of the lumbar spine: verification and validation with 18 specimen-specific models. J Biomech 49(13):2669-2676. https://doi.org/10.1016/j.jbiom ech.2016.05.025

Cao L, Liu Y, Mei W, Xu J, Zhan S (2020) Biomechanical changes of degenerated adjacent segment and intact lumbar spine after lumbosacral topping-off surgery: a three-dimensional finite element analysis. BMC Musculoskelet Disord 21(1):104

Charles YP, Lima LVPC, Persohn S, Rouch P, Steib JP, Skalli W (2013) Influence of an auxiliary facet system on intervertebral discs and adjacent facet joints. Spine J 13(10):1293-1300. https://doi.org/10.1016/j.spinee.2013.06.019

Chen CS, Cheng CK, Liu CL (2002) A biomechanical comparison of posterolateral fusion and posterior fusion in the lumbar spine. J Spinal Disord Tech. https://doi.org/10.1097/00024720-20020 2000-00010

Chen SH, Zhong ZC, Chen CS, Chen WJ, Hung C (2009) Biomechanical comparison between lumbar disc arthroplasty and fusion. Med Eng Phys 31(2):244-253. https://doi. org/10.1016/j.medengphy.2008.07.007

Chen JW, Chen WC, Lai YS, Chang CM, Wang ST (2015) Effect of a novel compressible artificial disk on biomechanical performance of cervical spine: a finite element study. Adv Mech Eng 7(8):1-5. https://doi.org/10.1177/1687814015602597

Cheung JTM, Zhang M, Chow DHK (2003) Biomechanical responses of the intervertebral joints to static and vibrational loading: a finite element study. Clin Biomech 18(9):790-799. https://doi. org/10.1016/S0268-0033(03)00142-6

Choi J, Kim S, Shin DA (2016) Biomechanical comparison of spinal fusion methods using interspinous process compressor and pedicle screw fixation system based on finite element method. J Korean Neurosurg Soc 59(2):91

Choi J, Shin DA, Kim S (2017) Biomechanical effects of the geometry of ball-and-socket artificial disc on lumbar spine: a finite element study. Spine 42(6):E332-E339

Chuang WH, Lin SC, Chen SH, Wang CW, Tsai WC, Chen YJ, Hwang JR (2012) Biomechanical effects of disc degeneration and hybrid fixation on the transition and adjacent lumbar segments: trade-off between junctional problem, motion preservation, and load protection. Spine 37(24):E1488-E1497

Cooper RJ, Wilcox RK, Jones AC (2019) Finite element models of the tibiofemoral joint: a review of validation approaches and modelling challenges. Med Eng Phys 74:1-12. https://doi. org/10.1016/j.medengphy.2019.08.002

Deng Z, Wang K, Wang H, Lan T, Zhan H, Niu W (2017) A finite element study of traditional chinese cervical manipulation. Eur Spine J 26(9):2308-2317. https://doi.org/10.1007/s0058 6-017-5193-5

Dreischarf M, Zander T, Shirazi-Adl A, Puttlitz C, Adam C, Chen C, Goel V, Kiapour A, Kim Y, Labus K, Little J, Park W, Wang Y, Wilke H, Rohlmann A, Schmidt H (2014) Comparison of eight published static finite element models of the intact lumbar spine: predictive power of models improves when combined together. J Biomech 47(8):1757-1766. https://doi.org/10.1016/j.jbiom ech.2014.04.002

Du CF, Yang N, Guo JC, Huang YP, Zhang C (2016a) Biomechanical response of lumbar facet joints under follower preload: a finite element study. BMC Musculoskelet Disord. https://doi. org/10.1186/s12891-016-0980-4

Du H, Liao S, Jiang Z, Huang H, Ning X, Jiang N, Pei J, Huang Q, Wei $\mathrm{H}$ (2016b) Biomechanical analysis of press-extension technique on degenerative lumbar with disc herniation and staggered facet joint. Saudi Pharm J 24(3):305-311. https://doi.org/10.1016/j. jsps.2016.04.002

Erdemir A, Besier TF, Halloran JP, Imhauser CW, Laz PJ, Morrison TM, Shelburne KB (2019) Deciphering the "art" in modeling and simulation of the knee joint: overall strategy. J Biomech Eng 141(7):0710021-07100210

Ezquerro F, Vacas FG, Postigo S, Prado M, Simón A (2011) Calibration of the finite element model of a lumbar functional spinal unit using an optimization technique based on differential evolution. Med Eng Phys 33(1):89-95. https://doi.org/10.1016/j.meden gphy.2010.09.010

Galbusera F, Bellini CM, Raimondi MT, Fornari M, Assietti R (2008) Cervical spine biomechanics following implantation of a disc prosthesis. Med Eng Phys 30(9):1127-1133. https://doi. org/10.1016/j.medengphy.2008.02.002

Gellhorn AC, Katz JN, Suri P (2013) Osteoarthritis of the spine: the facet joints. Nat Rev Rheumatol 9(4):216-224. https://doi. org/10.1038/nrrheum.2012.199

Ghezelbash F, Schmidt H, Shirazi-Adl A, El-Rich M (2020) Internal load-sharing in the human passive lumbar spine: review of in vitro and finite element model studies. J Biomech 102:109441. https://doi.org/10.1016/j.jbiomech.2019.109441

Goel VK, Kim YE, Lim TH, Weinstein JN (1988) An analytical investigation of the mechanics of spinal instrumentation. Spine (Phila Pa 1976) 13(9):1003-1011. https://doi.org/10.1097/00007632198809000-00007

Goto K, Tajima N, Chosa E, Totoribe K, Kuroki H, Arizumi Y, Arai T (2002) Mechanical analysis of the lumbar vertebrae in a threedimensional finite element method model in which intradiscal pressure in the nucleus pulposus was used to establish the model. J Orthop Sci 7(2):243-246. https://doi.org/10.1007/s007760200 040

Guilak F (2005) The slippery slope of arthritis. Arthritis Rheum 52(6):1632-1633 
Guo LX, Li WJ (2019) A biomechanical investigation of thoracolumbar burst fracture under vertical impact loads using finite element method. Clin Biomech 68:29-36. https://doi.org/10.1016/j.clinb iomech.2019.05.018

Guo LX, Li WJ (2020) Finite element modeling and static/dynamic validation of thoracolumbar-pelvic segment. Comput Methods Biomech Biomed Eng 23(2):69-80

Guo LX, Zhang M, Teo EC (2007) Influences of denucleation on contact force of facet joints under whole body vibration. Ergonomics 50(7):967-978. https://doi.org/10.1080/00140130701283943

Guo TM, Lu J, Xing YL, Liu GX, Zhu HY, Yang L, Qiao XM (2019) A 3-dimensional finite element analysis of adjacent segment disk degeneration induced by transforaminal lumbar interbody fusion after pedicle screw fixation. World Neurosurg 124:e51e57. https://doi.org/10.1016/j.wneu.2018.11.195

Henninger HB, Reese SP, Anderson AE, Weiss JA (2010) Validation of computational models in biomechanics. Proc Inst Mech Eng Part H J Eng Med 224(7):801-812

Holzapfel G, Stadler M (2006) Role of facet curvature for accurate vertebral facet load analysis. Eur Spine J 15(6):849-856. https ://doi.org/10.1007/s00586-004-0874-2

Huang X, Ye L, Wu Z, Liang L, Wang Q, Yu W, Liang D, Jiang $X$ (2018) Biomechanical effects of lateral bending position on performing cervical spinal manipulation for cervical disc herniation: a three-dimensional finite element analysis. Evid Based Complement Altern Med. https://doi. org/10.1155/2018/2798396

Hussain M, Natarajan R, An H, Andersson G (2010) Patterns of height changes in anterior and posterior cervical disc regions affects the contact loading at posterior facets during moderate and severe disc degeneration: a poroelastic c5-c6 finite element model study. Spine 35(18):E873-E881. https://doi.org/10.1097/ BRS.0b013e3181dc60a9

Jaumard NV, Bauman JA, Weisshaar CL, Guarino BB, Welch WC, Winkelstein BA (2011a) Contact pressure in the facet joint during sagittal bending of the cadaveric cervical spine. J Biomech Eng 133(7):071004

Jaumard NV, Welch WC, Winkelstein BA (2011b) Spinal facet joint biomechanics and mechanotransduction in normal, injury and degenerative conditions. J Biomech Eng 133(7):71010-NaN

John J, Yoganandan N, Arun M, Saravana Kumar G (2018) Influence of morphological variations on cervical spine segmental responses from inertial loading. Traffic Injury Prev 19:S29-S36. https:// doi.org/10.1080/15389588.2017.1403017

Jones AC, Wilcox RK (2008) Finite element analysis of the spine: towards a framework of verification, validation and sensitivity analysis. Med Eng Phys 30(10):1287-1304. https://doi. org/10.1016/j.medengphy.2008.09.006

Kang H, Park P, La Marca F, Hollister S, Lin CY (2010) Analysis of load sharing on uncovertebral and facet joints at the c5-6 level with implantation of the bryan, prestige lp, or prodisc-c cervical disc prosthesis: an in vivo image-based finite element study. Neurosurg Focus 28(6):1-8. https://doi.org/10.3171/2010.3.FOCUS 1046

Kang KT, Kim HJ, Son J, Yeom JS, Chun HJ (2015) Comparing an instrumented posterior fixation system with rigid and semi-flexible rods using finite element analysis. Int $\mathrm{J}$ Precis Eng Manuf 16(1):163-170. https://doi.org/10.1007/s12541-015-0021-5

Kang KT, Koh YG, Son J, Yeom JS, Park JH, Kim HJ (2017) Biomechanical evaluation of pedicle screw fixation system in spinal adjacent levels using polyetheretherketone, carbon-fiber-reinforced polyetheretherketone, and traditional titanium as rod materials. Compos Part B Eng 130:248-256. https://doi.org/10.1016/j. compositesb.2017.07.052

Khoddam-Khorasani P, Arjmand N, Shirazi-Adl A (2018) Trunk hybrid passive-active musculoskeletal modeling to determine the detailed t12-s1 response under in vivo loads. Ann Biomed Eng 46(11):1830-1843. https://doi.org/10.1007/s10439-018-2078-7

Kim YE, Goel VK, Weinstein JN, Lim TH (1991) Effect of disc degeneration at one level on the adjacent level in axial mode. Spine 16(3):331-335

Kim T, Kang K, Yoon D, Shin H, Kim K, Yi S, Chun H, Oh J, Choi G, Lee K, Ha Y (2012) Effects of lumbar arthrodesis on adjacent segments: differences between surgical techniques. Spine 37(17):1456-1462. https://doi.org/10.1097/BRS.0b013e3182 4da81d

Kim HJ, Chun HJ, Lee HM, Kang KT, Lee CK, Chang BS, Yeom JS (2013) The biomechanical influence of the facet joint orientation and the facet tropism in the lumbar spine. Spine J 13(10):13011308. https://doi.org/10.1016/j.spinee.2013.06.025

Kim HJ, Kang KT, Park SC, Kwon OH, Son J, Chang BS, Lee CK, Yeom JS, Lenke LG (2017) Biomechanical advantages of robotassisted pedicle screw fixation in posterior lumbar interbody fusion compared with freehand technique in a prospective randomized controlled trial-perspective for patient-specific finite element analysis. Spine J 17(5):671-680. https://doi.org/10.1016/j. spinee.2016.11.010

Kim YH, Khuyagbaatar B, Kim K (2018) Recent advances in finite element modeling of the human cervical spine. J Mech Sci Technol 32(1):1-10. https://doi.org/10.1007/s12206-017-1201-2

Kong W, Goel V, Gilbertson L, Weinstein J (1996) Effects of muscle dysfunction on lumbar spine mechanics: a finite element study based on a two motion segments model. Spine 21(19):21972207. https://doi.org/10.1097/00007632-199610010-00004

Kong W, Goel V, Gilbertson L (1998) Prediction of biomechanical parameters in the lumbar spine during static sagittal plane lifting. J Biomech Eng 120(2):273-280. https://doi.org/10.1115/1.27983 12

Kosalishkwaran G, Parasuraman S, Singh D, Natarajan E, Elamvazuthi I, George J (2019) Measurement of range of motions of 13-14 healthy spine through offsetting reflective markers and in silico analysis of meshed model. Med Biol Eng Comput 57(10):23052318. https://doi.org/10.1007/s11517-019-02026-6

Lee SH, Im YJ, Kim KT, Kim YH, Park WM, Kim K (2011) Comparison of cervical spine biomechanics after fixed- and mobilecore artificial sisc replacement: A finite element analysis. Spine 36(9):700-708. https://doi.org/10.1097/BRS.0b013e3181f5cb87

Lee J, Park W, Kim Y, Jahng TA (2016) A biomechanical analysis of an artificial disc with a shock-absorbing core property by using whole-cervical spine finite element analysis. Spine 41(15):E893E901. https://doi.org/10.1097/BRS.0000000000001468

Li Y, Fogel G, Liao Z, Tyagi R, Zhang G, Liu W (2017a) Biomechanical analysis of two-level cervical disc replacement with a standalone u-shaped disc implant. Spine 42(20):E1173-E1181. https ://doi.org/10.1097/BRS.0000000000002128

Li Y, Fogel GR, Liao Z, Liu W (2017b) Finite element model predicts the biomechanical performance of cervical disc replacement and fusion hybrid surgery with various geometry of ball-and-socket artificial disc. Int J Comput Assist Radiol Surg 12(8):1399-1409. https://doi.org/10.1007/s11548-017-1616-3

Li Y, Zhang Z, Liao Z, Mo Z, Liu W (2017c) Finite element analysis of influence of axial position of center of rotation of a cervical total disc replacement on biomechanical parameters: simulated 2-level replacement based on a validated model. World Neurosurg 106:932-938. https://doi.org/10.1016/j.wneu.2017.07.079

Li Y, Zhu J, Liao Z, Zhang Z, Liu W (2018) Hybrid constructs for performing three-level hybrid surgery: a finite element study. World Neurosurg 114:e1302-e1309. https://doi.org/10.1016/j. wneu.2018.03.202

Li J, Zhang X, Xu W, Xi Z, Xie L (2019) Reducing the extent of facetectomy may decrease morbidity in failed back surgery 
syndrome. BMC Musculoskelet Disord. https://doi.org/10.1186/ s12891-019-2751-5

Li XR, Yu J, Zhang W, Gao GM, Han L, Chen L, Nong LM (2020) Biomechanical model study of the effect of partial facetectomy on lumbar stability under percutaneous endoscopy. World Neurosurg 139:e255-e264

Lin CY, Chuang SY, Chiang CJ, Tsuang YH, Chen WP (2014) Finite element analysis of cervical spine with different constrained types of total disc replacement. J Mech Med Biol. https://doi. org/10.1142/S0219519414500389

Liu CL, Zhong ZC, Hsu HW, Shih SL, Wang ST, Hung C, Chen CS (2011) Effect of the cord pretension of the dynesys dynamic stabilisation system on the biomechanics of the lumbar spine: a finite element analysis. Eur Spine J 20(11):1850-1858

Liu CW, Wang LL, Xu YK, Chen CM, Wang JC, Tsai WT, Lin SC (2020) Traditional and cortical trajectory screws of static and dynamic lumbar fixation-a finite element study. BMC Musculoskelet Disord. https://doi.org/10.21203/rs.2.17440/v3

Liu T, Khalaf K, Naserkhaki S, El-Rich M (2018) Load-sharing in the lumbosacral spine in neutral standing and flexed posturesa combined finite element and inverse static study. J Biomech 70:43-50. https://doi.org/10.1016/j.jbiomech.2017.10.033

Lo HJ, Chen CS, Chen HM, Yang SW (2019) Application of an interspinous process device after minimally invasive lumbar decompression could lead to stress redistribution at the pars interarticularis: a finite element analysis. BMC Musculoskelet Disord. https ://doi.org/10.1186/s12891-019-2565-5

Mengoni M (2020a) Literature review: methods and validation of facet joints biomechanics in finite element models. [dataset, University of Leeds, https://doi.org/10.5518/925]

Mengoni M (2020b) Using inverse finite element analysis to identify spinal tissue behaviour in situ. Methods. https://doi. org/10.1016/j.ymeth.2020.02.004

Mengoni M, Vasiljeva K, Jones AC, Tarsuslugil SM, Wilcox RK (2016) Subject-specific multi-validation of a finite element model of ovine cervical functional spinal units. J Biomech 49(2):259266. https://doi.org/10.1016/j.jbiomech.2015.12.005

Mengoni M, Kayode O, Sikora SNF, Zapata-Cornelio FY, Gregory DE, Wilcox RK (2017) Annulus fibrosus functional extrafibrillar and fibrous mechanical behaviour: experimental and computational characterisation. R Soc Open Sci 4(8):170807. https://doi. org/10.1098/rsos.170807

Mesfar W, Moglo K (2013) Effect of the transverse ligament rupture on the biomechanics of the cervical spine under a compressive loading. Clin Biomech 28(8):846-852. https://doi.org/10.1016/j. clinbiomech.2013.07.016

Mills M, Sarigul-Klijn N (2019) Validation of an in vivo medical image-based young human lumbar spine finite element model. J Biomech Eng. https://doi.org/10.1115/1.4042183

Mo Z, Li Q, Jia Z, Yang J, Wong DC, Fan Y (2017) Biomechanical consideration of prosthesis selection in hybrid surgery for bi-level cervical disc degenerative diseases. Eur Spine J Off Publ Eur Spine Soc Eur Spinal Deform Soc Eur Sect Cerv Spine Res Soc 26(4):1181-1190. https://doi.org/10.1007/s00586-016-4777-9

Morrison TM, Hariharan P, Funkhouser CM, Afshari P, Goodin M, Horner M (2019) Assessing computational model credibility using a risk-based framework: application to hemolysis in centrifugal blood pumps. Asaio J 65(4):349

Moumene M, Geisler F (2007) Comparison of biomechanical function at ideal and varied surgical placement for two lumbar artificial disc implant designs: mobile-core versus fixed-core. Spine 32(17):1840-1851. https://doi.org/10.1097/BRS.0b013e3181 1 ec $29 \mathrm{c}$

Mustafy T, El-Rich M, Mesfar W, Moglo K (2014) Investigation of impact loading rate effects on the ligamentous cervical spinal load-partitioning using finite element model of functional spinal unit c2-c3. J Biomech 47(12):2891-2903. https://doi. org/10.1016/j.jbiomech.2014.07.016

Naserkhaki S, Jaremko JL, Adeeb S, El-Rich M (2016) On the loadsharing along the ligamentous lumbosacral spine in flexed and extended postures: finite element study. J Biomech 49(6):974982. https://doi.org/10.1016/j.jbiomech.2015.09.050

Niemeyer F, Wilke HJ, Schmidt H (2012) Geometry strongly influences the response of numerical models of the lumbar spine-a probabilistic finite element analysis. J Biomech 45(8):1414-1423. https ://doi.org/10.1016/j.jbiomech.2012.02.021

Nikkhoo M, Cheng CH, Wang JL, Khoz Z, El-Rich M, Hebela N, Khalaf K (2019) Development and validation of a geometrically personalized finite element model of the lower ligamentous cervical spine for clinical applications. Comput Biol Med 109:2232. https://doi.org/10.1016/j.compbiomed.2019.04.010

Nikkhoo M, Khoz Z, Cheng CH, Niu CC, El-Rich M, Khalaf K (2020) Development of a novel geometrically-parametric patient-specific finite element model to investigate the effects of the lumbar lordosis angle on fusion surgery. J Biomech 102:109722. https ://doi.org/10.1016/j.jbiomech.2020.109722

Niosi CA, Wilson DC, Zhu Q, Keynan O, Wilson DR, Oxland TR (2008) The effect of dynamic posterior stabilization on facet joint contact forces: an in vitro investigation. Spine 33(1):19-26

Noailly J, Wilke HJ, Planell JA, Lacroix D (2007) How does the geometry affect the internal biomechanics of a lumbar spine bisegment finite element model? Consequences on the validation process. J Biomech 40(11):2414-2425. https://doi.org/10.1016/j. jbiomech.2006.11.021

Noailly J, Ambrosio L, Tanner K, Planell J, Lacroix D (2012) In silico evaluation of a new composite disc substitute with a 13-15 lumbar spine finite element model. Eur Spine J 21(SUPPL. 5):S675S687. https://doi.org/10.1007/s00586-011-1716-7

O'Leary SA, Paschos NK, Link JM, Klineberg EO, Hu JC, Athanasiou KA (2018) Facet joints of the spine: structure-function relationships, problems and treatments, and the potential for regeneration. Annu Rev Biomed Eng 20(1):145-170. https:// doi.org/10.1146/annurev-bioeng-062117-120924

Ottardi C, Galbusera F, Luca A, Prosdocimo L, Sasso M, BraydaBruno M, Villa T (2016) Finite element analysis of the lumbar destabilization following pedicle subtraction osteotomy. Med Eng Phys 38(5):506-509. https://doi.org/10.1016/j.meden gphy.2016.02.002

Panzer MB, Cronin DS (2009) C4-c5 segment finite element model development, validation, and load-sharing investigation. J Biomech 42(4):480-490. https://doi.org/10.1016/j.jbiom ech.2008.11.036

Park W, Kim Y, Lee S (2013a) Effect of intervertebral disc degeneration on biomechanical behaviors of a lumbar motion segment under physiological loading conditions. J Mech Sci Technol 27(2):483-489. https://doi.org/10.1007/s12206-012-1264-z

Park WM, Kim K, Kim YH (2013b) Effects of degenerated intervertebral discs on intersegmental rotations, intradiscal pressures, and facet joint forces of the whole lumbar spine. Comput Biol Med 43(9):1234-1240. https://doi.org/10.1016/j.compbiomed .2013.06.011

Pathria M, Sartoris DJ, Resnick D (1987) Osteoarthritis of the facet joints: accuracy of oblique radiographic assessment. Radiology 164(1):227-230. https://doi.org/10.1148/radiology.164.1.35889 10

Pitzen T, Geisler F, Matthis D, Müller-Storz H, Barbier D, Steudel WI, Feldges A (2002) A finite element model for predicting the biomechanical behaviour of the human lumbar spine. Control Eng Pract 10(1):83-90. https://doi.org/10.1016/S0967 $-0661(01) 00129-0$ 
Rohlmann A, Bauer L, Zander T, Bergmann G, Wilke HJ (2006a) Determination of trunk muscle forces for flexion and extension by using a validated finite element model of the lumbar spine and measured in vivo data. J Biomech 39(6):981-989. https:// doi.org/10.1016/j.jbiomech.2005.02.019

Rohlmann A, Zander T, Schmidt H, Wilke HJ, Bergmann G (2006b) Analysis of the influence of disc degeneration on the mechanical behaviour of a lumbar motion segment using the finite element method. J Biomech 39(13):2484-2490. https://doi.org/10.1016/j. jbiomech.2005.07.026

Rong X, Wang B, Ding C, Deng Y, Chen H, Meng Y, Yan W, Liu $H$ (2017) The biomechanical impact of facet tropism on the intervertebral disc and facet joints in the cervical spine. Spine $\mathbf{J}$ 17(12):1926-1931. https://doi.org/10.1016/j.spinee.2017.07.009

Rundell SA, Isaza JE, Kurtz SM (2011) Biomechanical evaluation of a spherical lumbar interbody device at varying levels of subsidence. SAS J 5(1):16-25. https://doi.org/10.1016/j. esas.2010.12.001

Sawa AG, Crawford NR (2008) The use of surface strain data and a neural networks solution method to determine lumbar facet joint loads during in vitro spine testing. J Biomech 41(12):2647-2653

Schmidt H, Galbusera F, Rohlmann A, Zander T, Wilke HJ (2012) Effect of multilevel lumbar disc arthroplasty on spine kinematics and facet joint loads in flexion and extension: a finite element analysis. Eur Spine J 21(SUPPL. 5):S663-S674. https:// doi.org/10.1007/s00586-010-1382-1

Schmidt H, Bashkuev M, Dreischarf M, Rohlmann A, Duda G, Wilke HJ, Shirazi-Adl A (2013) Computational biomechanics of a lumbar motion segment in pure and combined shear loads. $\mathrm{J}$ Biomech 46(14):2513-2521. https://doi.org/10.1016/j.jbiom ech.2013.06.038

Sharma MA, Langrana NA, Rodriguez JA (1995) Role of ligaments and facets in lumbar spinal stability. Spine 20(8):887-900

Shen H, Fogel GR, Zhu J, Liao Z, Liu W (2019) Biomechanical analysis of different lumbar interspinous process devices: a finite element study. World Neurosurg 127:e1112-e1119. https://doi. org/10.1016/j.wneu.2019.04.051

Shirazi-Adl A (1994) Biomechanics of the lumbar spine in sagittal/ lateral moments. Spine 19(21):2407-2414

Shirazi-Adl A, Drouin G (1987) Load-bearing role of facets in a lumbar segment under sagittal plane loadings. J Biomech 20(6):601-613. https://doi.org/10.1016/0021-9290(87)90281-8

Shirazi-Adl A, Ahmed A, Shrivastava S (1986) A finite element study of a lumbar motion segment subjected to pure sagittal plane moments. J Biomech 19(4):331-350. https://doi. org/10.1016/0021-9290(86)90009-6

Song C, Li XF, Liu ZD, Zhong GB (2014) Biomechanical assessment ofanovel 14/5 level interspinous implant using three dimensional finite element analysis. Eur Rev Med Pharmcol Sci 18(1):86-94

Song XX, Jin LY, Li XF, Qian L, Shen HX, Liu ZD, Yu BW (2018) Effects of low bone mineral status on biomechanical characteristics in idiopathic scoliotic spinal deformity. World Neurosurg 110:e321-e329. https://doi.org/10.1016/j.wneu.2017.10.177

Sterba M, Aubin CÉ, Wagnac E, Fradet L, Arnoux PJ (2019) Effect of impact velocity and ligament mechanical properties on lumbar spine injuries in posterior-anterior impact loading conditions: a finite element study. Med Biol Eng Comput 57(6):1381-1392. https://doi.org/10.1007/s11517-019-01964-5

Suarez-Escobar M, Rendon-Velez E (2018) A survey on static and quasi-static finite element models of the human cervical spine. Int J Interact Design Manuf (IJIDeM) 12(2):741-765. https://doi. org/10.1007/s12008-017-0431-y

Sun X, Sun S, Zhang T, Kong C, Wang W, Lu S (2020) Biomechanical comparison of noncontiguous cervical disc arthroplasty and noncontiguous cervical discectomy and fusion in the treatment of noncontinuous cervical degenerative disc disease: a finite element analysis. J Orthop Surg Res 15(1):36

Tang S, Meng X (2011) Does disc space height of fused segment affect adjacent degeneration in alif? A finite element study. Turk Neurosurg 21(3):296-303. https://doi.org/10.5137/1019-5149. JTN.4018-10.0

Teo E, Ng H (2001) Evaluation of the role of ligaments, facets and disc nucleus in lower cervical spine under compression and sagittal moments using finite element method. Med Eng Phys 23(3):155164. https://doi.org/10.1016/S1350-4533(01)00036-4

Teo E, Lee K, Ng H, Qiu T, Yang K (2003) Determination of load transmission and contact force at facet joints of 12-13 motion segment using FE method. J Musculoskelet Res 7(2):97-109. https://doi.org/10.1142/S0218957703001034

Tsouknidas A, Sarigiannidis S, Anagnostidis K, Michailidis N, Ahuja S (2015) Assessment of stress patterns on a spinal motion segment in healthy versus osteoporotic bony models with or without disc degeneration: a finite element analysis. Spine J 15(3):S17-S22. https://doi.org/10.1016/j.spinee.2014.12.148

Viceconti M, Pappalardo F, Rodriguez B, Horner M, Bischoff J, Musuamba Tshinanu F (2020) In silico trials: verification, validation and uncertainty quantification of predictive models used in the regulatory evaluation of biomedical products. Methods. https://doi.org/10.1016/j.ymeth.2020.01.011

Wang J, Parnianpour M, Shirazi-Adl A, Engin A, Li S, Patwardhan A (1997) Development and validation of a viscoelastic finite element model of an 12/13 motion segment. Theor Appl Fract Mech 28(1):81-93. https://doi.org/10.1016/S0167-8442(97)00032-3

Wang W, Zhang H, Sadeghipour K, Baran G (2013) Effect of posterolateral disc replacement on kinematics and stress distribution in the lumbar spine: a finite element study. Med Eng Phys 35:357-64. https://doi.org/10.1016/j.medengphy.2012.05.013

Wang L, Zhang B, Chen S, Lu X, Li ZY, Guo Q (2016a) A validated finite element analysis of facet joint stress in degenerative lumbar scoliosis. World Neurosurg 95:126-133. https://doi. org/10.1016/j.wneu.2016.07.106

Wang Z, Zhao H, Liu J-M, Tan L-W, Liu P, Zhao J-H (2016b) Resection or degeneration of uncovertebral joints altered the segmental kinematics and load-sharing pattern of subaxial cervical spine: a biomechanical investigation using a c2-t1 finite element model. J Biomech 49(13):2854-2862. https://doi.org/10.1016/j.jbiom ech.2016.06.027

Wang W, Sun X, Zhang T, Sun S, Kong C, Lu S (2020) Toppingoff technology versus posterior lumbar interbody fusion in the treatment of lumbar disc herniation: a meta-analysis. BioMed Res Int: 10

Wilson DC, Niosi CA, Zhu QA, Oxland TR, Wilson DR (2006) Accuracy and repeatability of a new method for measuring facet loads in the lumbar spine. J Biomech 39(2):348-353. https:// doi.org/10.1016/j.jbiomech.2004.12.011

Woldtvedt D, Womack W, Gadomski B, Schuldt D, Puttlitz C (2011) Finite element lumbar spine facet contact parameter predictions are affected by the cartilage thickness distribution and initial joint gap size. J Biomech Eng. https://doi.org/10.1115/1.4004287

Wu W, Chen C, Ning J, Sun P, Zhang J, Wu C, Bi Z, Fan J, Lai X, Ouyang J (2017) A novel anterior transpedicular screw artificial vertebral body system for lower cervical spine fixation: A finite element study. J Biomech Eng. https://doi.org/10.1115/1.40363 93

Xin-Feng L, Lin-Yu J, Chao-Ge L, Hong-Ling Y, Xiao-Xing S (2020) Adjacent-level biomechanics after single-level anterior cervical interbody fusion with anchored zero-profile spacer versus cageplate construct: a finite element study. BMC Surg 20(1):1-11

Xu M, Yang J, Lieberman IH, Haddas R (2017) Lumbar spine finite element model for healthy subjects: development and validation. 
Comput Methods Biomech Biomed Eng 20(1):1-15. https://doi. org/10.1080/10255842.2016.1193596

Yang K, King A (1984) Mechanism of facet load transmission as a hypothesis for low-back pain. Spine 9(6):557-565. https://doi. org/10.1097/00007632-198409000-00005

Yu Y, Zhou Q, Yz Xie, Xl Wang, Fan Xh, Dw Gu, Huang X, Wu Wd (2020) Effect of percutaneous endoscopic lumbar foraminoplasty of different facet joint portions on lumbar biomechanics: a finite element analysis. Orthop Surg 12:1277-1284

Yuchi CX, Sun G, Chen C, Liu G, Zhao D, Yang H, Xu B, Deng S, Ma X, Du CF, Yang Q (2019) Comparison of the biomechanical changes after percutaneous full-endoscopic anterior cervical discectomy versus posterior cervical foraminotomy at c5-c6: a finite element-based study. World Neurosurg 128:e905-e911. https:// doi.org/10.1016/j.wneu.2019.05.025

Zeng ZL, Zhu R, Wu YC, Zuo W, Yu Y, Wang JJ, Cheng LM (2017) Effect of graded facetectomy on lumbar biomechanics. J Healthc Eng. https://doi.org/10.1155/2017/7981513

Zhang Z, Li H, Fogel GR, Liao Z, Li Y, Liu W (2018) Biomechanical analysis of porous additive manufactured cages for lateral lumbar interbody fusion: a finite element analysis. World Neurosurg 111:e581-e591. https://doi.org/10.1016/j.wneu.2017.12.127

Zhou Q, Zeng F, Tu J, Dong Z, Ding ZH (2020) Influence of cementaugmented pedicle screw instrumentation in an osteoporotic lumbosacral spine over the adjacent segments: a $3 \mathrm{~d}$ finite element study. J Orthop Surg Res 15(1):132
Zhu QA, Park YB, Sjovold SG, Niosi CA, Wilson DC, Cripton PA, Oxland TR (2008) Can extra-articular strains be used to measure facet contact forces in the lumbar spine? an in-vitro biomechanical study. Proc Inst Mech Eng Part H J Eng Med 222(2):171-184. https://doi.org/10.1243/09544119JEIM290

Zhu Z, Liu C, Wang K, Zhou J, Wang J, Zhu Y, Liu H (2015) Toppingoff technique prevents aggravation of degeneration of adjacent segment fusion revealed by retrospective and finite element biomechanical analysis. J Orthop Surg Res 10(1):10. https://doi. org/10.1186/s13018-014-0142-Z

Zhu R, Niu W-X, Zeng Z-L, Tong J-H, Zhen Z-W, Zhou S, Yu Y, Cheng L-M (2017) The effects of muscle weakness on degenerative spondylolisthesis: a finite element study. Clin Biomech 41:34-38. https://doi.org/10.1016/j.clinbiomech.2016.11.007

Zhu H, Zhong W, Zhang P, Liu X, Huang J, Liu F, Li J (2020) Biomechanical evaluation of autologous bone-cage in posterior lumbar interbody fusion: a finite element analysis. BMC Musculoskelet Disord 21(1):1-12

Publisher's Note Springer Nature remains neutral with regard to jurisdictional claims in published maps and institutional affiliations. 